\title{
ROLE OF GLASS MELT FLOW IN CONTAINER FURNACE EXAMINED BY MATHEMATICAL MODELLING
}

\author{
"MARCELA JEBAVÁ, LUBOMÍR NĚMEC \\ Laboratory of Inorganic Materials, joint workplace of the University of Chemistry and Technology Prague, \\ 16628 Prague, and the Institute of Rock Structure and Mechanics of the ASCR, v.v.i., 18209 Prague, Czech Republic \\ ${ }^{\#}$ E-mail: Marcela.Jebava@vscht.cz
}

Submitted September 14, 2017; accepted October 16, 2017

Keywords: Glass melting, Mathematical modeling, Energy distribution, Space utilization, Melting performance, Heat losses

The character of the glass melt flow in a regenerative container furnace was simulated by mathematical modeling under conditions of various energy distributions in the melting space with the application of electric boosting. The aim was the achievement of high melting performance and the decrease of heat losses. The results of the modeling have confirmed that the melting performance generally increased and heat losses decreased with the growth of the total amount of energy added to the batch region of the furnace. The amount of energy delivered to the furnace batch region moved between $30-60 \%$ of the total supplied energy; the melting performance then corresponded with 230 - 460 tons/day, and the specific heat losses were between $1450-2100 \mathrm{~kJ} \cdot \mathrm{kg}^{-1}$ of glass. The energetic model of melt flows is presented providing the diagram of various flow characters.

\section{INTRODUCTION}

Much effort has been devoted to the examination of melting kinetics either by a theoretical approach and laboratory experiments [1-11] or by mathematical modeling under conditions of the flowing melt [12-15]; we will mention only a few of them. Cooper [16] discussed the role of longitudinal and transversal melt circulations in the horizontal melting space on the course of the homogenization phenomena and underlined the urgent need of criteria enabling to find optimal flow behavior. Several patents [17-22] proposed means that beneficially affect the melt flow with respect to melting capacity and quality; however, no general rules for setting up the desired melt flow were provided.

When the problem of the quantitative evaluation of the melt flow character arose, a new quantity called utilization of the space $u$ was introduced [23-27]. The values of the space utilization can be incorporated in the relations calculating the melting performance and specific energy consumption. Besides the uniform flow, the helical character of the flow was found to be efficient in spaces with set temperature fields. The maximal utilization values were mostly $0.6-0.8$ [25]; however, melting under the presence of the longitudinal melt circulations in an industrial melting furnace indicated values only around $0.05-0.07$.

Mathematical modeling applying heat source was subsequently realized in a small orthogonal channel [28]. The colder raw glass melt with undissolved sand particles and bubbles simulated the batch. The primarily intensive counterclockwise longitudinal melt circulations faded and space utilization, as well as melting performance, increased with the fraction of energy delivered in the input region. This work is focused on the application of the obtained results in the industrial furnace. The effects of the detailed flow arrangement will also be investigated.

\section{THEORETICAL}

The utilization of the space $u_{H}$ (the index $H$ designates the relevant homogenization process - sand dissolution or bubble removal) expresses the relation between the reference homogenization time at a given temperature regime $\tau_{\text {Href }}$ and the mean residence time of the melt in the space under critical conditions $\tau_{G}$ [23-27]. Thus, $\tau_{G}$ is given by the ratio between the space volume and volume flow rate (see Equation 1). The critical state describes the situation when the first particle of the critical size, sand or bubble, attains the space output. The first of the two parallel phenomena attaining the output is the controlling one. The $u_{H}$ value is defined as follows:

$$
u_{H}=\frac{\tau_{H r e f}}{\tau_{G}}, \tau_{G}=\frac{v}{\dot{v}}, u \in\langle 0 ; 1\rangle
$$

where $V$ is the volume of the space $\left(\mathrm{m}^{3}\right)$ and $\dot{V}$ is the volume flow rate (melting performance or pull rate) $\left(\mathrm{m}^{3} \cdot \mathrm{s}^{-1}\right)$. If the controlling phenomenon is sand dissolution, then $\tau_{\text {Href }}=\tau_{\text {Dave }}$, whereas $\tau_{\text {Href }}=\tau_{\text {Fref }}$ is valid when bubble removal is controlling. The quantity $\tau_{\text {Fref }}$ is the fining time which the critical bubble needs to ascend the distance $h_{0}$ 
in a quiescent liquid at the average temperature in the space. The details of the $\tau_{F r e f}$ calculation are given in [24], Equation 6. $\tau_{\text {Dave }}$ is the average sand dissolution time.

The specific heat losses of the space through boundaries decrease and the performance of the glass melting process increases with the space utilization:

$$
\begin{gathered}
H_{M}^{L}=\frac{\dot{H}^{L} \tau_{\text {Dave }}}{\rho V} \frac{1}{u_{D}}=\frac{\dot{H}^{L}}{\dot{M}} \text { or } H_{M}^{L}=\frac{\dot{H}^{L} \tau_{\text {Fref }}}{\rho V} \frac{1}{u_{F}}=\frac{\dot{H}^{L}}{\dot{M}} \\
\dot{V}=\frac{V u_{D}}{\tau_{\text {Dave }}} \text { or } \dot{V}=\frac{V u_{F}}{\tau_{\text {Fref }}}
\end{gathered}
$$

where $H_{M}^{L}$ are the specific heat losses $\left(\mathrm{J} \cdot \mathrm{kg}^{-1}\right), \dot{H}^{L}$ is the total heat flux across the space boundaries $\left(\mathrm{J} \cdot \mathrm{s}^{-1}\right)$, and $\rho$ is the glass density $\left(\mathrm{kg} \cdot \mathrm{m}^{-3}\right)$. The nucleation of bubbles during the process is not considered.

The space utilization for both phenomena may be expressed with the assistance of fractions of actual or virtual dead spaces [23] but only the utilization values will be used in this work.

The quantities defined by equations (1-3) may be acquired by modeling the critical state of bubble removal or sand dissolution in the melting space with adjusted flow patterns. The resulting character of the melt flow particularly depends on the horizontal distribution of the energy supplied in the space [28]. If a horizontal melting space is divided into the input part including the batch region and the following part under free melt level, the amount of energy may be defined in each part, corresponding to the balanced energetic state. For the region of the free level holds:

$$
\dot{H}_{L}(1-\xi)=\left(1-k_{1}\right)\left(H_{M}^{T} \dot{M}_{b a l}+\dot{H}^{L}\right)
$$

where $\dot{H}^{L}$ is the total heat flux through space boundaries (i.e. heat losses) in $\mathrm{kW}, \xi$ is the fraction of heat losses belonging to the input region, $H_{M}^{T}$ is the energy for batch reactions, phase and modification transitions and for heating of the contents to the space exit temperature (theoretical heat) in $\mathrm{kJ} \cdot \mathrm{kg}^{-1}, \dot{M}_{b a l}$ is a melt flow rate in the balanced state $\left(\mathrm{kg} \cdot \mathrm{s}^{-1}\right)$ and $k_{l}$ is the fraction of heat flux really absorbed by the batch and glass in the batch region; its value is defined by:

$$
k_{1}=\dot{H}_{\text {batch }} / \dot{H}_{\text {batch glass }}
$$

where $\dot{H}_{\text {batch }}$ is the heat flux absorbed by the batch region and $\dot{H}_{\text {batch glass }}$ is the total absorbed energy.

If the right side of Equation 4, representing the actually delivered energy in the free level part, is greater than the theoretically needed heat losses, represented by the left part of equation, the counter-clockwise longitudinal circulations develop in the space. Hence the clockwise circulations establish when right side will be smaller than the left one.

The melt flow rate corresponding to the energetically balanced state and characterized by the uniform flow of the melt is derived from equation (4):

$$
\dot{M}_{b a l}=\frac{\dot{H}^{L}\left(k_{1}-\xi\right)}{H_{M}^{T}\left(1-k_{1}\right)}
$$

As is apparent, $\dot{M}_{b a l}=0$ for $k_{1}=\xi$ and $\dot{M}_{b a l} \rightarrow \infty$ for $k_{l} \rightarrow 1$. Considering Equation 6, the $\dot{M}$ values situated above (or left) the curve of $\dot{M}_{b a l}\left(k_{l}\right)$ belong to the counter-clockwise longitudinal circulations of the melt and the values below this curve (or right) to the clockwise circulations. The model of the melt flow characters based on the energy distribution is called "energetic" in this work.

\section{Calculation procedure and conditions}

The regenerative U-flame container glass melting furnace with two side inputs (chargers) of the batch and electric boosting was chosen as a representative real melting space for the calculations. The perspective view of the melting part of the furnace is presented in Figure 1. Glass Furnace Model (Glass Service, Inc.) was used for mathematical modeling.

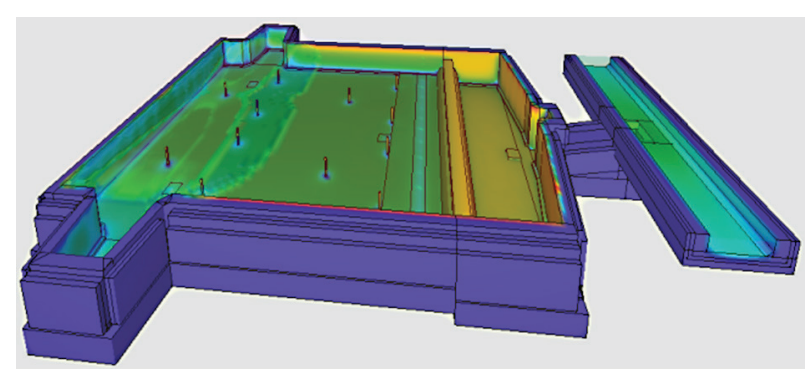

Figure 1. The perspective view of the modelled regenerative glass melting furnace for the production of container glass with two side batch chargers, heated by $2 \times 4$ burners located in the combustion space in the front wall, and with a deep refiner. The arrangement of the boosting vertical electrodes and the use of a transversal row of bubbling nozzles before the barrier characterize the reference case.

Only the melting part of the furnace, extending to the transversal refractory barrier behind the bubbling, was used for the calculation of sand dissolution and bubble removal. The maximal inner length $\mathrm{X}$ of the whole furnace was $12.4 \mathrm{~m}$ and the modelled melting space was $9.9 \mathrm{~m}$ long (to the barrier), width $\mathrm{Y}$ amounted to $8 \mathrm{~m}$ (without the side inputs), and the maximal thickness of the glass $\mathrm{H}$ was $1.22 \mathrm{~m}$. The total volume of the melting part with side inputs was $100.05 \mathrm{~m}^{3}$. 4-5 layers of refractory materials formed the walls and bottom of the space. The height of boosting electrodes was in most cases $0.6 \mathrm{~m}$. The average temperature of glass inside the melting space was maintained at $1387^{\circ} \mathrm{C}$. The transversal barrier made from the refractory material behind the bubbling line served as the reference mark 
where the critical state was achieved. The melt input and output velocities had full- and half-parabolic profiles, the non-slip conditions, i.e. the zero melt velocities were assumed on the solid boundaries, and the free level conditions on the boundary between the atmosphere and glass melt.

The already previously examined float type of glass was chosen as the model glass because the compositions of the float and container glasses were similar. The temperature dependence of the glass density and kinema- tic viscosity in the temperature interval $900-1800^{\circ} \mathrm{C}$ is presented in [29]. The glass batch with $50 \%$ of cullet was applied; the covered part of the melt level demarcated the batch region of the furnace. The average sand dissolution rate and the average bubble growth rates obtained by laboratory experiments were used to follow the history of both phenomena in the furnace. The temperature dependences of both average rates are as well presented in [29]. The semiempirical model of bubble behavior was applied [29].

Table 1. The overall views of the melting part of container furnace with various arrangements of electrodes.

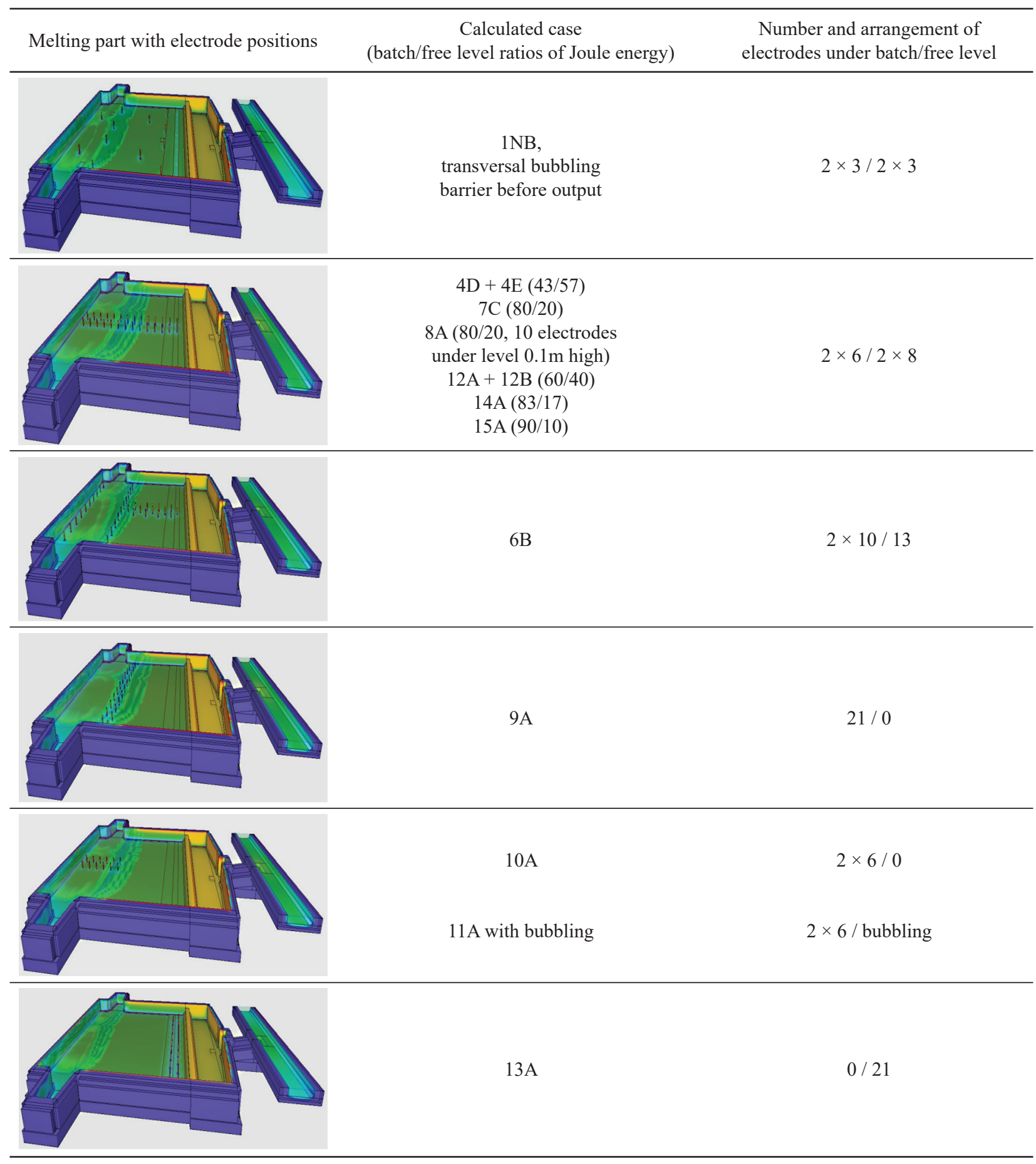


The bubbles with an initial radius of $5 \times 10^{-5} \mathrm{~m}$ were chosen as the smallest ones and the sand particles of $5 \times 10^{-4} \mathrm{~m}$ as the maximal ones. The history of around $10^{4}$ bubbles and sand particles with randomly located starting points at the boundary between the batch and melt (bubbles) and at the input of the batch (sand particles, valid data from $1250^{\circ} \mathrm{C}$ ) were followed.

To achieve the critical state, the flow rate of the melt was varied at an otherwise constant ratio $k_{1}$. The accomplished controlling phenomenon determined the critical mass melting performance, the mean residence time of the melt in the space $\tau_{G}$, and the average sand dissolution time $\tau_{\text {Dave }}$. The value of $\tau_{\text {Fref }}$ was obtained from Equation 6 in [24] and the values of both space utilizations from Equation 1. The melting performance and the specific energy consumption, possibly specific heat losses, were acquired from equation (2).

The reference case corresponded to the industrial application. The following cases were aimed at shifting a larger part of boosting energy into the batch region and at simulating the helical flow using various arrangements of the electrodes.

\section{RESULTS}

The following views of the furnace in Table $1 \mathrm{re}$ present the calculated cases with different arrangements of heating electrodes. Moreover, the transversal bubbling barrier was applied in case 1NB whereas the central longitudinal bubbling barrier in the free level region was an extension of the row of electrodes in case 11A. The positions of the electrodes in Table 1 are designated by small vertical lines.

The overall modelling results are summarized in the following Tables 2 and 3 where the former provides the melting performances and the energetic and temperature balance whereas the latter provides the sand dissolution and bubble removal values together with values characterizing the space utilization.

The typical trajectories of the melt in the projections $\mathrm{XY}$ and XZ are given in Figures 2-4 and the typical critical trajectories are presented in Figure 5.

Table 3. The values characterizing the space utilization in the calculated cases. The average value of the reference fining times $\tau_{\mathrm{F} \text { ref }}$ is $4150 \mathrm{~s}$. The bold characters designate the controlling phenomenon.

\begin{tabular}{lcccc}
\hline case & $\tau_{G}(\mathrm{~s})$ & $\tau_{\text {Dave }}(\mathrm{s})$ & $u_{D}$ & $u_{F}$ \\
\hline 1NB & 85507 & 5864 & $\mathbf{0 . 0 6 9}$ & 0.048 \\
4D & 59588 & 5308 & 0.089 & $\mathbf{0 . 0 7 0}$ \\
4E & 59581 & 5664 & 0.095 & $\mathbf{0 . 0 6 8}$ \\
6B & 49155 & 5639 & 0.115 & $\mathbf{0 . 0 8 5}$ \\
7C & 46816 & 5644 & 0.121 & $\mathbf{0 . 0 8 8}$ \\
8A & 49779 & 5500 & 0.110 & $\mathbf{0 . 0 8 3}$ \\
9A & 46820 & 5635 & $\mathbf{0 . 1 2 0}$ & 0.089 \\
10A & 51754 & 5344 & $\mathbf{0 . 1 0 3}$ & 0.080 \\
11A & 51754 & 5508 & $\mathbf{0 . 1 0 6}$ & 0.080 \\
12A & 56180 & 5606 & 0.100 & $\mathbf{0 . 0 7 4}$ \\
12B & 56180 & 5665 & 0.101 & $\mathbf{0 . 0 7 4}$ \\
13A & 78658 & 5830 & 0.074 & $\mathbf{0 . 0 5 3}$ \\
14A & 46821 & 5472 & 0.117 & $\mathbf{0 . 0 8 9}$ \\
15A & 42749 & 5180 & 0.121 & $\mathbf{0 . 0 9 7}$ \\
\hline
\end{tabular}

\section{DISCUSSION}

Two factors were examined in the calculations of the space utilization and melting performance: the effect of the longitudinal distribution of the supplied energy and the effect of the energetic support of the helical flow. The dimensionless criterion was introduced as an auxiliary quantity which describes to what degree the shape of a melt trajectory approaches the helical form.

Table 2. The critical melting performance $\dot{M}_{c r i t}$ and the energetic, as well as temperature balance of the calculated cases $\left(H_{M}^{0}-\right.$ - specific energy consumption, $H_{M}^{L}$ - specific heat losses by boundaries, $\dot{H}_{\text {Joule }}$ - Joule heat flux in the furnace, $\dot{H}_{\text {comb tot }}-$ heat flux delivered by burners in the furnace, $\dot{H}_{t o t}-$ total heat flux delivered in the furnace.

\begin{tabular}{|c|c|c|c|c|c|c|c|c|c|}
\hline case & $\begin{array}{c}\dot{M}_{c r i t} \\
\text { (tons/day) }\end{array}$ & $\begin{array}{c}H_{M}^{0} \\
\left(\mathrm{~kJ} \cdot \mathrm{kg}^{-1}\right)\end{array}$ & $\begin{array}{c}H_{M}^{L} \\
\left(\mathrm{~kJ} \cdot \mathrm{kg}^{-1}\right)\end{array}$ & $\begin{array}{l}T_{\text {crown }} \\
\left({ }^{\circ} \mathrm{C}\right)\end{array}$ & $\begin{array}{l}T_{\text {level }} \\
\left({ }^{\circ} \mathrm{C}\right)\end{array}$ & $\begin{array}{l}\dot{H}_{\text {Joule }} \\
(\mathrm{kW})\end{array}$ & $\begin{array}{c}\dot{H}_{\text {comb tot }} \\
(\mathrm{kW})\end{array}$ & $\begin{array}{c}\dot{H}_{t o t} \\
(\mathrm{~kW})\end{array}$ & $\dot{H}_{\text {Joule }} / \dot{H}_{t o t}$ \\
\hline$\overline{1 \mathrm{NB}}$ & 230 & 4411 & 2099 & 1506 & 1472 & 846 & 10895 & 11741 & 0.072 \\
\hline $4 \mathrm{D}$ & 330 & 4143 & 1830 & 1540 & 1503 & 1393 & 14431 & 15824 & 0.088 \\
\hline $4 \mathrm{E}$ & 330 & 3968 & 1669 & 1519 & 1493 & 2091 & 13063 & 15154 & 0.138 \\
\hline $6 \mathrm{~B}$ & 400 & 3875 & 1568 & 1540 & 1505 & 2689 & 15250 & 17939 & 0.150 \\
\hline $7 \mathrm{C}$ & 420 & 3860 & 1552 & 1550 & 1511 & 2789 & 15975 & 18764 & 0.149 \\
\hline $8 \mathrm{~A}$ & 395 & 3848 & 1546 & 1536 & 1503 & 2778 & 14816 & 17594 & 0.158 \\
\hline $9 \mathrm{~A}$ & 420 & 3849 & 1544 & 1547 & 1512 & 2789 & 15919 & 18709 & 0.149 \\
\hline $10 \mathrm{~A}$ & 380 & 3946 & 1642 & 1547 & 1512 & 2092 & 15265 & 17357 & 0.121 \\
\hline $11 \mathrm{~A}$ & 380 & 3935 & 1632 & 1544 & 1508 & 2092 & 15216 & 17308 & 0.121 \\
\hline $12 \mathrm{~A}$ & 350 & 3928 & 1617 & 1522 & 1494 & 2391 & 13523 & 15914 & 0.150 \\
\hline $12 \mathrm{~B}$ & 350 & 4020 & 1715 & 1539 & 1511 & 1793 & 14492 & 16285 & 0.110 \\
\hline $13 \mathrm{~A}$ & 250 & 4349 & 2041 & 1519 & 1485 & 766 & 11818 & 12583 & 0.061 \\
\hline $14 \mathrm{~A}$ & 420 & 3764 & 1466 & 1532 & 1499 & 3307 & 14990 & 18297 & 0.181 \\
\hline $15 \mathrm{~A}$ & 460 & 3747 & 1454 & 1548 & 1506 & 3486 & 16463 & 19949 & 0.175 \\
\hline
\end{tabular}




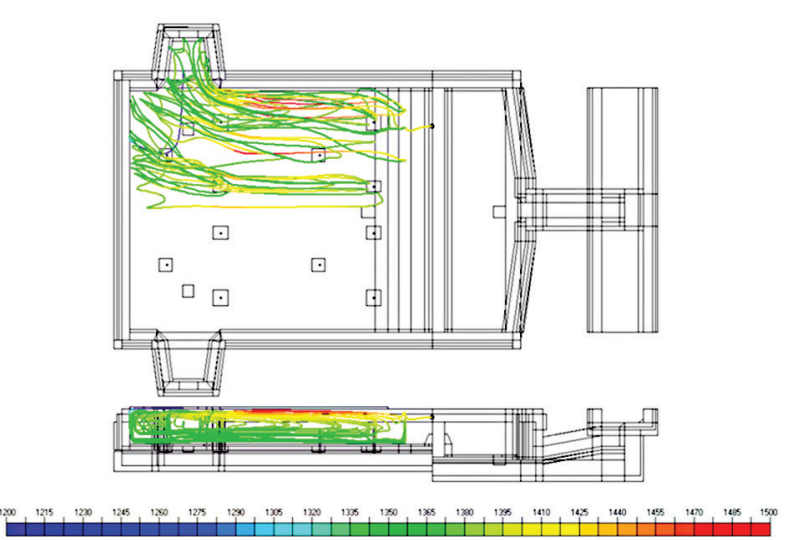

a) $1 \mathrm{NB}$

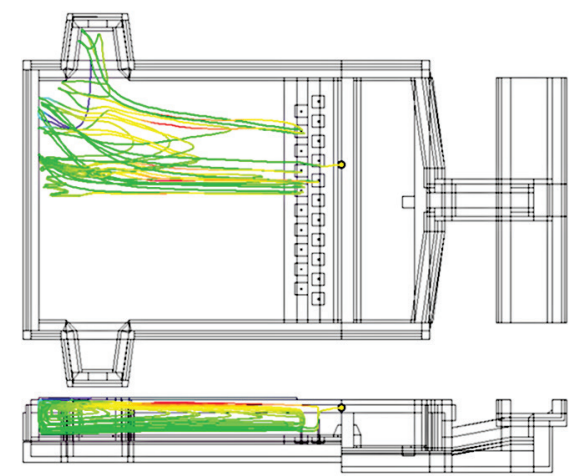

b) $13 \mathrm{~A}$

Figure 2. The shapes of the melt trajectory in cases with predominant longitudinal circulations. a) case $1 \mathrm{NB}$, one melt trajectory of the length of $390 \mathrm{~m}$; b) case 13A, one melt trajectory of the length of $303 \mathrm{~m}$. Temperature scale is in ${ }^{\circ} \mathrm{C}$.

The "helicality" $A$ of a melt trajectory is defined as the ratio between the length run by a melt element in the $y$-direction to the length run in the $x$-direction of a trajectory:

$$
A=\frac{\sum_{i=1}^{n}\left|v_{y i}\right| \Delta \tau}{\sum_{i=1}^{n}\left|v_{x i}\right| \Delta \tau}
$$

where $v_{y i}$ is the $y$-velocity component of the melt and $v_{x i}$ is the $x$-velocity component in the $i$-th calculation step of each trajectory, and $n$ is the number of calculation steps. The value of $A$ is zero in the uniform flow, and is much higher than 1 in the developed helical flow. The average values of $A$ including all the examined trajectories will be used.

The calculated cases with various electrode arrangements were ranked and compared in two classes: the cases with the predominating longitudinal circulations evoked by transversal electrode groups or rows $1 \mathrm{NB}$, $9 \mathrm{~A}$, and $13 \mathrm{~A}$, and the cases with supported transversal circulations realized by the double central longitudinal row of electrodes 4D, 4E, 7C, 8A, 10A, 11A, 12A, 12B, $14 \mathrm{~A}$, and $15 \mathrm{~A}$. Case $6 \mathrm{~B}$ is a mixed one. The second class of arrangements involves heating either along the entire

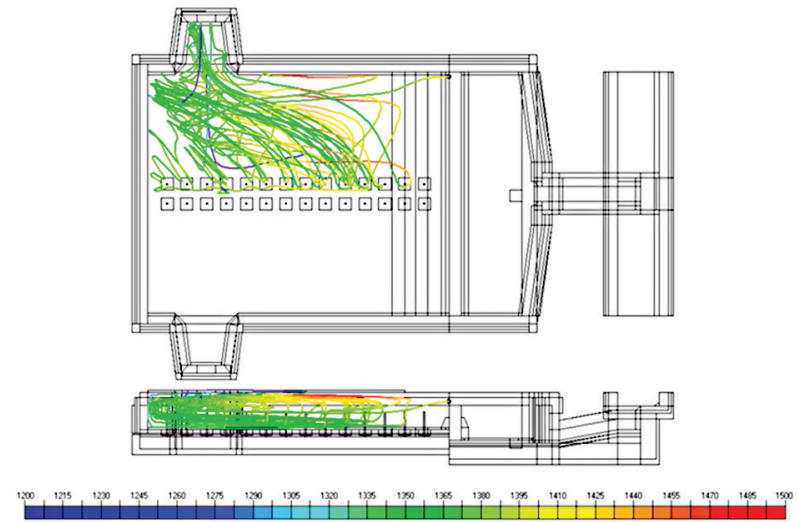

a) $12 \mathrm{~A}$

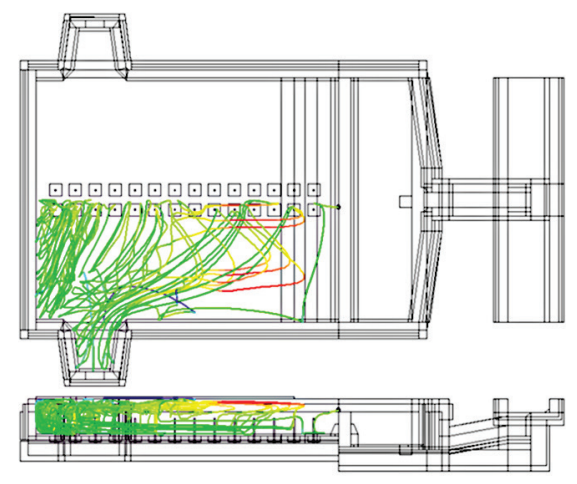

b) $7 \mathrm{C}$

Figure 3. The shapes of the melt trajectory in cases with predominant spiral trajectories. a) case $12 \mathrm{~A}$, one melt trajectory of the length of $440 \mathrm{~m}$; b) case $7 \mathrm{C}$, one melt trajectory of the length of $420 \mathrm{~m}$.

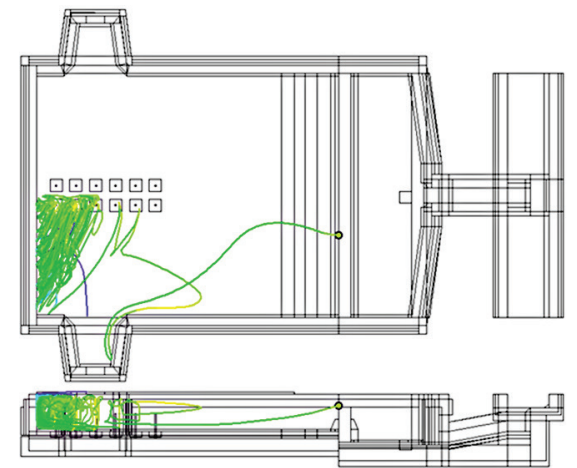

Figure 4. The shapes of the melt trajectory in the case with $100 \%$ of Joule energy located under the batch. Case 10A, length of the melt trajectory is $350 \mathrm{~m}$.

space length or only along the batch region (cases 10A and $11 \mathrm{~A}$ ). The shapes of typical melt trajectories are presented in Figures 2-4. The difference between Figures 2 and 3 demonstrates the transition to the melt spiral flow when the longitudinal heating barrier is applied. 
The maximum average values of the longitudinal melt circulation velocity in the bottom stream $v_{x \max }$ were read for all the measurements and summarized in Table 4, details of reading are in the legend to Table 4. The typical shapes of critical trajectories are in Figure 5, projections XZ. In the first class with the transversal electrode arrangement, the average value of $v_{x \max }$ apparently decreases when a part or all of the Joule energy is located in the batch region. The decrease of the $v_{x \max }$ from the value $2.65 \mathrm{~mm} \cdot \mathrm{s}^{-1}$ in case $13 \mathrm{~A}$ ( or $2.63 \mathrm{~mm} \cdot \mathrm{s}^{-1}$ for the case $1 \mathrm{NB}$ ) to the value of $2.22 \mathrm{~mm} \cdot \mathrm{s}^{-1}$ in case 9A is accompanied by the increase of the space utilization (see both $u_{D}$ and $u_{F}$ in Table 3 ) and melting performance (from 250 or 230 tons/day to 420 tons/day, see Table 3). The values of the auxiliary criterion $A$ of flow helicality in Table 4 are expectedly low for all three cases.

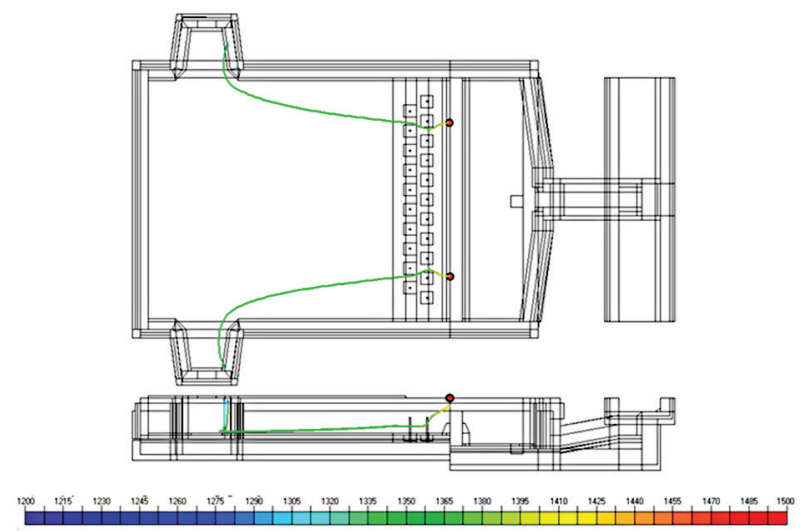

a) $13 \mathrm{~A}$

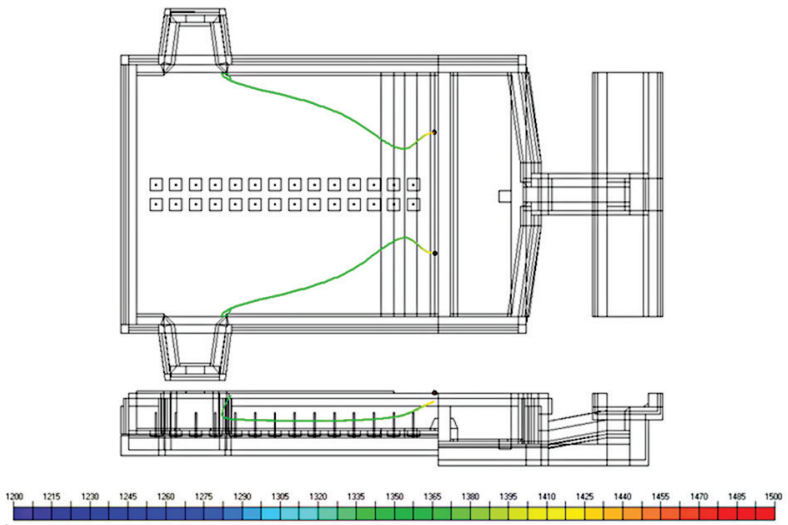

b) $7 \mathrm{C}$

Figure 5. The typical run of critical bubble trajectories in $\mathrm{XY}$ and $\mathrm{XZ}$ projections. a) case 13A (predominant longitudinal circulations), b) case 7C (predominant spiral circulations).
The maximal melt velocity $v_{x \max }$ decreases also in the second class with the longitudinal double row of electrodes when the fraction of Joule energy located under the batch increases. The relevant values of $v_{x \max }$ in cases $4 \mathrm{D}, 4 \mathrm{E}$ ( $43 \%$ of the Joule energy under the batch), $12 \mathrm{~A}, 12 \mathrm{~B}(60 \%), 7 \mathrm{C}(80 \%), 14 \mathrm{~A}(83 \%)$, and 15A $(90 \%)$ are presented in Table 4 and depicted in Figure 6 along with the values of the critical melting performance. The critical melting performance increases here with decreasing $v_{x \max }$ as expected. The values of utilization $u_{F}$ in Table 3 correspondingly grow from the value of 0.068 to 0.097 . The auxiliary criterion of helicality $A$ in Table 4 shows an increase from the average value of 0.69 to 1.30 . However, it appears difficult to distinguish the effect of the energy transfer to the batch region (the decrease of $v_{x \max }$ ) from the effect of established transversal circulations indicated by the high value of $A$.

The cases with the support of the transversal melt circulations only under the batch (cases 10A, 11A) show a strong circulation effect in the batch region where $100 \%$ of Joule energy is located. The melt trajectories nevertheless show a clear forward direction without a helical flow in the region under the free level (see Figure 4), under the otherwise low value of $v_{x \max }$. The melting performance decreases with respect to cases with the complete longitudinal electrode rows, the reason being either in the fading melt circularity under free level or in the lower amount of Joule energy applied. Neither can the significance of particular effects be distinguished.

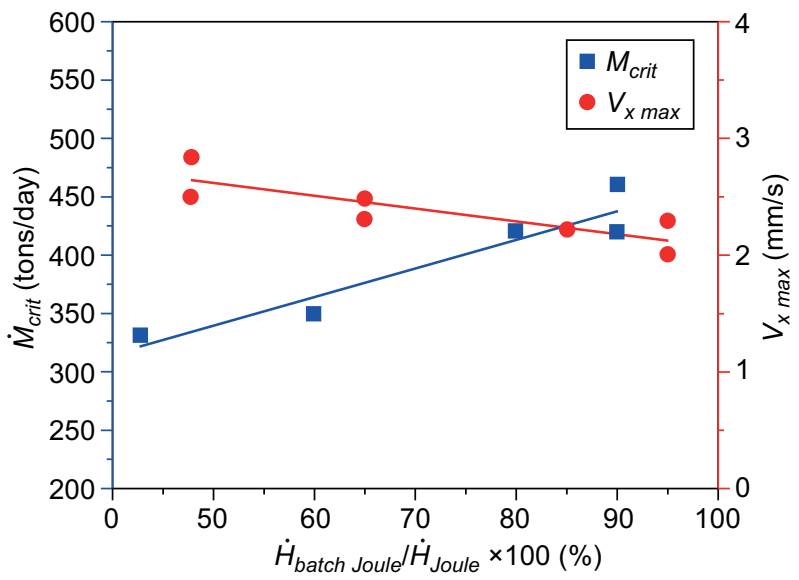

Figure 6. The dependence of the maximal melt velocity in $x$-direction $v_{x \max }$ and the critical mass melting performance $\dot{M}_{c r i t}$ on the percentage of the Joule energy supplied to the longitudinal rows of electrodes in the batch region of the furnace.

Table 4. The values of the average maximal velocity of the melt forward flow $v_{x \max }$ and the criteria of flow helicality A. The values of $v_{x \max }$ were obtained in the $1 / 4(3 / 4)$ of the space width to avoid the impact of the central longitudinal row of electrodes in cases $4 \mathrm{D}, 4 \mathrm{E}, 6 \mathrm{~B}, 7 \mathrm{C}, 8 \mathrm{~A}, 10 \mathrm{~A}, 11 \mathrm{~A}, 12 \mathrm{~A}, 12 \mathrm{~B}, 14 \mathrm{~A}$, and $15 \mathrm{~A}$, and at $\mathrm{X}=5000,6000,7000$, and $8000 \mathrm{~mm}$ from the inner front wall to avoid the impact of transversal rows of electrodes in cases $1 \mathrm{NB}, 9 \mathrm{~A}$, and $13 \mathrm{~A}$.

\begin{tabular}{lcccccccccccccc}
\hline case & $1 \mathrm{NB}$ & $4 \mathrm{D}$ & $4 \mathrm{E}$ & $6 \mathrm{~B}$ & $7 \mathrm{C}$ & $8 \mathrm{~A}$ & $9 \mathrm{~A}$ & $10 \mathrm{~A}$ & $11 \mathrm{~A}$ & $12 \mathrm{~A}$ & $12 \mathrm{~B}$ & $13 \mathrm{~A}$ & $14 \mathrm{~A}$ & $15 \mathrm{~A}$ \\
\hline$v_{x \max }\left(\mathrm{mm} \cdot \mathrm{s}^{-1}\right)$ & 2.63 & 2.50 & 2.84 & 2.18 & 2.22 & 2.09 & 2.22 & 1.86 & 1.79 & 2.49 & 2.31 & 2.65 & 2.29 & 2.01 \\
$A$ & 0.48 & 0.78 & 0.69 & 0.65 & 1.05 & 1.09 & 0.51 & 0.96 & 1.01 & 0.79 & 0.71 & 0.45 & 1.21 & 1.30 \\
\hline
\end{tabular}


No effect of bubbling on the melting was apparent in case 11A. Generally, both the location of a substantial amount of the Joule energy under the batch and the high values of criterion $A$ indicate higher space utilization and melting performance. However, it appeared difficult to define the significance of the Joule energy transfer and flow helicality separately by use of the results in their existing form.

To determine the role of the energy distribution and helical flow for the melting process, the distribution of the combustion heat should be taken into consideration, as well. The relevant values of quantities were found from the furnace heat balance and are published in Table 5 .

Thus, the fraction of heat absorbed in the batch region $k_{l}$ is given by:

$$
k_{1}=\frac{\dot{H}_{\text {batch comb }}+\dot{H}_{\text {batch Joule }}}{\dot{H}_{\text {batch comb }}+\dot{H}_{\text {batch Joule }}+\dot{H}_{\text {glass comb }}+\dot{H}_{\text {glass Joule }}}
$$

And the fraction of energy delivered in the batch region $K$ is:

$$
K=\frac{\dot{H}_{\text {batch tot }}}{\dot{H}_{\text {tot }}}
$$

The amounts of energy absorbed from the combustion space by either the free level or batch were assessed from their level areas. The heat losses $\dot{H}^{L}$ were assessed for the melting part without the deep refiner. As the fraction of heat flux delivered in the batch region $\dot{H}_{\text {batch tot }}$, the sum of the Joule heat flux in the batch region $\dot{H}_{\text {batch Joule }}$, and the fraction of the total heat flux by burners $\dot{H}_{\text {comb tot }}$ (see Table 2) were considered. This fraction of $\dot{H}_{\text {comb tot }}$ was assumed proportional to the fraction of the level surfaces occupied by the batch in the entire furnace. Thus, both the values of $\dot{H}_{\text {glass comb }}, \dot{H}^{L}$, and $\dot{H}_{\text {batch tot }}$ represent only an approximation assuming homogeneous energy distribution in the combustion space and homogeneous distribution of the heat losses.

Using $k_{l}$, the values of the critical mass melting performance of all the calculations were plotted as a function of this quantity. Simultaneously, the curve of $\dot{M}_{b a l}\left(k_{1}\right)$ from Equation 7 was applicable. The critical melting performances in Figure 7 approximately extend between $k_{I}=0.5-0.8$ and show an almost linear increase, the increase being almost independent of the electrode arrangement in the space. The dependence $\dot{M}_{\text {crit }}(K)$ (values in Table 5) indicates the same character as $\dot{M}_{c r i t}\left(k_{1}\right)$, the values of $K$ fluctuating in most cases around 0.5 , the best cases being around 0.6 . The results prove the primary role of the longitudinal energy distribution for the melting performance.

Taking into account Equation 2a,b, the specific heat losses should decrease with increasing mass melting performance which is obvious from Figure 7. Whereas the mass melting performance increased twice, the specific energy consumption decreased by $15 \%$ between cases $1 \mathrm{NB}$ and $15 \mathrm{~A}$. A more detailed inspection indicates

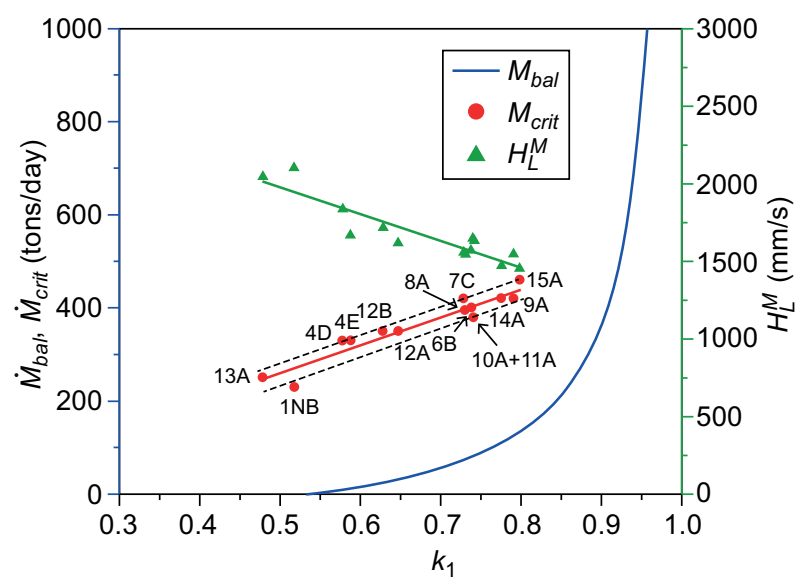

Figure 7. The values of the critical mass melting performance $\dot{M}_{\text {crit }}$, the specific heat losses $\dot{H}_{M}^{L}$, and the mass melting performance in the balanced energetic state $\dot{M}_{b a l}$ as functions of the fraction of energy absorbed by the batch region $k_{1}$. The average value of $\dot{H}^{L}=2654 \mathrm{~kW}$ (Table 5), the value of $H_{M}^{T}=2290 \mathrm{~kJ} \cdot \mathrm{kg}^{-1}$, and the value of $\xi=0.534$.

\begin{tabular}{|c|c|c|c|c|c|c|c|c|c|}
\hline case & $\begin{array}{l}\dot{H}_{t o t} \\
(k W)\end{array}$ & $\begin{array}{c}\dot{H}_{\text {batch comb }} \\
\quad(k W)\end{array}$ & $\begin{array}{c}\dot{H}_{\text {batch Joule }} \\
\quad(k W)\end{array}$ & $\begin{array}{c}\dot{H}_{\text {glass comb }} \\
\quad(k W)\end{array}$ & $\begin{array}{c}\dot{H}_{\text {glass Joule }} \\
\quad(k W)\end{array}$ & $\begin{array}{c}\dot{H}_{\text {batch tot }} \\
(\mathrm{kW})\end{array}$ & $\begin{array}{c}\dot{H}^{L} \\
(\mathrm{~kW})\end{array}$ & $k_{1}$ & $K$ \\
\hline $1 \mathrm{NB}$ & 11741 & 2645 & 348 & 2291 & 498 & 3712 & 2571 & 0.518 & 0.316 \\
\hline 4D & 15824 & 4059 & 597 & 2597 & 796 & 6205 & 2670 & 0.578 & 0.392 \\
\hline $4 \mathrm{E}$ & 15154 & 3902 & 896 & 2167 & 1195 & 6304 & 2623 & 0.588 & 0.416 \\
\hline $6 \mathrm{~B}$ & 17939 & 4943 & 2291 & 2187 & 398 & 9882 & 2695 & 0.737 & 0.540 \\
\hline $7 \mathrm{C}$ & 18764 & 5254 & 2231 & 2232 & 558 & 10023 & 2699 & 0.728 & 0.534 \\
\hline $8 \mathrm{~A}$ & 17594 & 4792 & 2240 & 2063 & 538 & 9773 & 2669 & 0.730 & 0.555 \\
\hline $9 \mathrm{~A}$ & 18709 & 5270 & 2789 & 2147 & 0 & 10895 & 2688 & 0.790 & 0.582 \\
\hline $10 \mathrm{~A}$ & 17357 & 4726 & 2092 & 2397 & 0 & 8997 & 2654 & 0.740 & 0.518 \\
\hline $11 \mathrm{~A}$ & 17308 & 4719 & 2092 & 2383 & 0 & 8999 & 2644 & 0.741 & 0.520 \\
\hline $12 \mathrm{~A}$ & 15914 & 4189 & 1434 & 2124 & 956 & 7334 & 2632 & 0.647 & 0.461 \\
\hline $12 \mathrm{~B}$ & 16285 & 4252 & 1076 & 2464 & 717 & 7265 & 2669 & 0.628 & 0.446 \\
\hline $13 \mathrm{~A}$ & 12583 & 2960 & 0 & 2453 & 766 & 3758 & 2577 & 0.479 & 0.300 \\
\hline $14 \mathrm{~A}$ & 18297 & 5115 & 2760 & 1737 & 547 & 10566 & 2666 & 0.775 & 0.577 \\
\hline $15 \mathrm{~A}$ & 19949 & 5726 & 3138 & 1894 & 349 & 12027 & 2703 & 0.798 & 0.603 \\
\hline
\end{tabular}

Table 5. The partial quantities for calculation of the fraction of energy located in the batch region $k_{1}$. 
that the longitudinal row of electrodes, particularly cases $4 \mathrm{D}, 4 \mathrm{E}, 7 \mathrm{C}, 12 \mathrm{~B}$, and 15A, show slightly higher values of the critical melting performance when compared with the cases characterized by the transversal electrode barriers, namely cases $1 \mathrm{NB}$ and 9A (see dashed lines in Figure 7). However, it is generally obvious that the helical flow played only a minor role for the given cases. As is seen from the transversal section through the space at $X=8000 \mathrm{~mm}$ in the following Figure 8, the development of the transversal circulations is disrupted near the level owing to very hot glass near the level. When the character of the flow is changed by the energy redistribution, both the space utilization and melting or fining times at the relevant time-temperature regime may be affected (see Equations 3a, b). The role of both types of quantities is obvious from Figure 9 where the absolute values of percentage changes of both space utilizations and average sand dissolution times are plotted against $k_{l}$. The dependences in Figure 9 show the noticeable growth of both utilization values with $k_{l}$ whereas the values of $\tau_{\text {Dave }}$ change only in a narrow range. Consequently, almost only the melt flow character is responsible for the growth of the mass melting performance and the decrease of specific heat losses.

The extension of the main linear dependence between $\dot{M}_{c r i t}$ and $k_{I}$ in Figure 7 intersects the curve $\dot{M}_{b a l}$

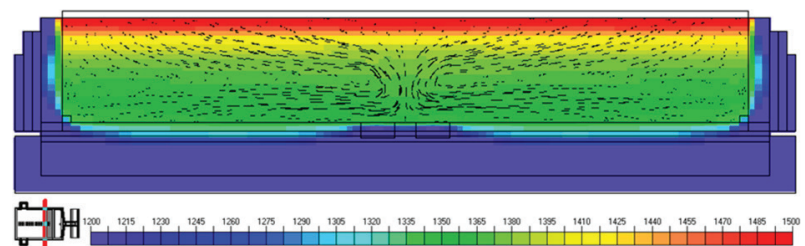

Figure 8 . The transversal section through the furnace at $\mathrm{X}=$ $=8000 \mathrm{~mm}$. Case 7C with the longitudinal rows of electrodes.

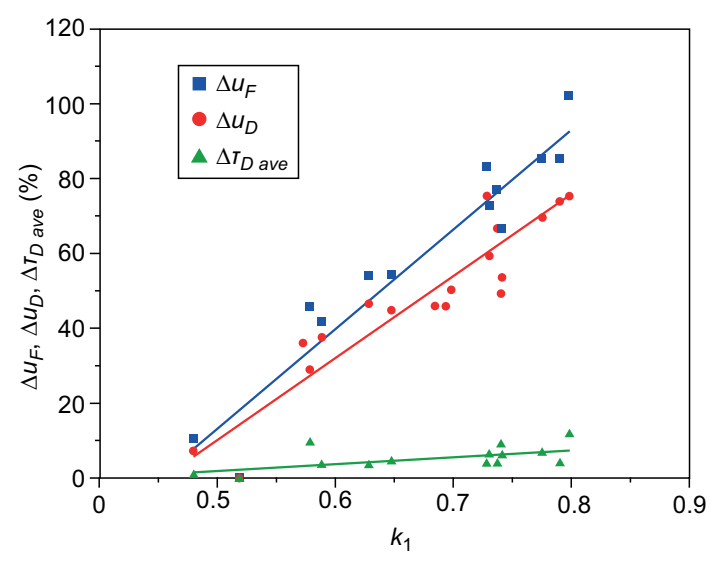

Figure 9. The absolute values of the percentage changes of the space utilization $u_{D}, u_{F}$, and the average sand dissolution time $\tau_{\text {Dave }}$ as a function of the fraction of energy absorbed by the batch region $k_{1}$. The values are related to the reference case 1NB. Straight lines show a general trend, only. behind $k_{l}=0.9$ and above $\dot{M}_{c r i t}=500$ tons/day. If the dependences were steadily linear, the cross sections of $\dot{M}_{c r i t}\left(k_{1}\right)$ and $\dot{M}_{b a l}\left(k_{1}\right)$ would roughly correspond to the maximal attainable melting performance at the balanced energy distribution. In fact, the function $\dot{M}_{c r i t}\left(k_{1}\right)$ should progressively grow as it approaches the region of the assumed uniform flow which is marked by the progressive growth of the space utilization and consequently, melting performance in [28]. Nevertheless, the calculation of the critical performance at highest values of $k_{l}$ showed problems resulting mostly from the extending batch area. A simplified energetic model of the $\dot{M}_{c r i t}$ $\left(k_{1}\right)$ dependence would be therefore useful for a credible extrapolation to the $\dot{M}_{b a l}\left(k_{1}\right)$ curve. The needed resulting longitudinal velocity component of the melt flow is defined by the sum of the velocity component caused by the through-flow $v_{f r}$ and by the longitudinal component of the natural circulation velocity $v_{l c}$. The velocity component $v_{f r}$ here has a positive value and proportionally grows with the flow rate: $v_{f r}=C_{2} \dot{M}$, where $C_{2}$ is the constant. The longitudinal circulation velocity component $v_{l c}$ expresses the overall intensity of longitudinal circulations; its driving force is described by the difference between the energy actually delivered in either input or free level region and energy needed in the relevant region of the space for maintaining the balanced state (see Equation 4). Its characteristic value is situated in the longitudinal level axis of the free level region and expresses there also the flow direction of the melt. The linear dependence between $v_{l c}$ and $k_{l}$ is assumed for the sake of simplicity:

$$
v_{l c}=-C_{1}\left[\left(1-k_{1}\right)\left(H_{M}^{T} \dot{M}+\dot{H}^{L}\right)-(1-\xi) \dot{H}^{L}\right]
$$

where $\mathrm{C}_{1}$ is the constant.

If $v_{l c}=0$, then $\dot{M}_{c r i t}=\dot{M}_{b a l}$ as is already apparent from Equation 4. No longitudinal circulation ideally exists in that case and the longitudinal flow would be uniform, described only by the through-flow component $v_{f r}$.

Taking into account Equation 3a, b, the critical mass melting performance can be obtained from the dependence:

$$
\dot{M}_{c r i t}=\frac{\varrho V}{\tau_{H r e f}} u_{H}\left[v_{l c}\left(k_{1}\right)\right]
$$

The utilization value $u_{H}$ is a function of $v_{l c}\left(k_{1}\right)$ and should increase with decreasing $v_{l c}$ because the decreasing $v_{l c}$ reduces dead spaces. For simplification, the linear function between the utilization values of the controlling phenomenon $u_{H}$ and the longitudinal circulation velocity component $v_{l c}$ was proposed. The extent of the equation validity is assumed between the reference value $v_{\text {lcref }}$ in the initial (reference) calculation point and the terminal point where $v_{l c}=0$. The latter limit of validity corresponds to the intersection between the curves $\dot{M}_{c r i t}\left(k_{1}\right)$ and $\dot{M}_{b a l}\left(k_{1}\right)$. Consequently, the proposed equation has the form:

$$
u_{H}=u_{H \text { uniform }}-\frac{u_{H \text { uniform }}-u_{H \text { ref }}}{\left|v_{\text {lc ref }}\right|}\left|v_{l c}\right|
$$


where $u_{H \text { uniform }}$ is the utilization value for the controlling phenomenon in the terminal point of equation validity, where $v_{l c}=0$ and where the uniform flow is assumed. The utilization values of the isothermal uniform flow for both sand dissolution and bubble removal are known [25] and may be used for this purpose. $u_{H r e f}$ is then the space utilization for the relevant controlling phenomenon in the reference point (onset of calculations). Equation 12 and Equation 10 are now substituted into 11 and solved for the unknown critical melting performance. The resulting equation presents $\dot{M}_{c r i t}$ as a function of $k_{l}$ calculated by the energetic model:

$$
\dot{M}_{\text {crit }}=\frac{\frac{\varrho V}{\tau_{H \text { ref }}}\left[u_{\text {H uniform }}+\frac{\left(u_{\text {H uniform }}-u_{H \text { ref }}\right)}{\left|v_{\text {lc ref }}\right|} C_{1} \dot{H}^{L}\left(k_{1}-\xi\right)\right]}{1+\frac{\varrho V}{\tau_{\text {Href }}} \frac{\left(u_{\text {H uniform }}-u_{H \text { ref }}\right)}{\left|v_{\text {lc ref }}\right|} C_{1} H_{M}^{T}\left(1-k_{1}\right)}
$$

The fit between the numerical values of $\dot{M}_{c r i t}$ and the values coming from Equation 13 can be now examined. The values of constants $C_{1}, C_{2}, u_{H r e f}$, and $v_{\text {lcref }}$ should be obtained from numeric calculation; the starting value of $u_{\text {Huniform }}$ is 0.445 from [25]. The value of $C_{1}$ and $C_{2}$ were determined from case $13 \mathrm{~A}$. The maximum through-flow melt velocity on the level was determined to be $2.754 \times 10^{-4} \mathrm{~m} \cdot \mathrm{s}^{-1}$ and the value of the constant $C_{2}$ was $9.52 \times 10^{-5} \mathrm{~m} \cdot \mathrm{kg}^{-1}$. The maximal total melt velocity on the level approximately in the middle of the length of the free level was $-3.3 \times 10^{-3} \mathrm{~m} \cdot \mathrm{s}^{-1}$. Consequently, the relevant value of $v_{\text {lcref }}$ was $-3.025 \times 10^{-3} \mathrm{~m} \cdot \mathrm{s}^{-1}$. The constant $C_{l}$ was then calculated from Equation 10 for case 13A where $k_{l}=0.479$ (see Tab. 5). The resulting value of $C_{I}=9.51 \times 10^{-10} \mathrm{~m} \cdot \mathrm{J}^{-1}$ was used for different $k_{I}$ in all the calculation cases. Using the average value of $\tau_{\text {Dave }}=5561 \mathrm{~s}$, the ascertained values of $C_{1}, C_{2}, u_{\text {Href }}$, and

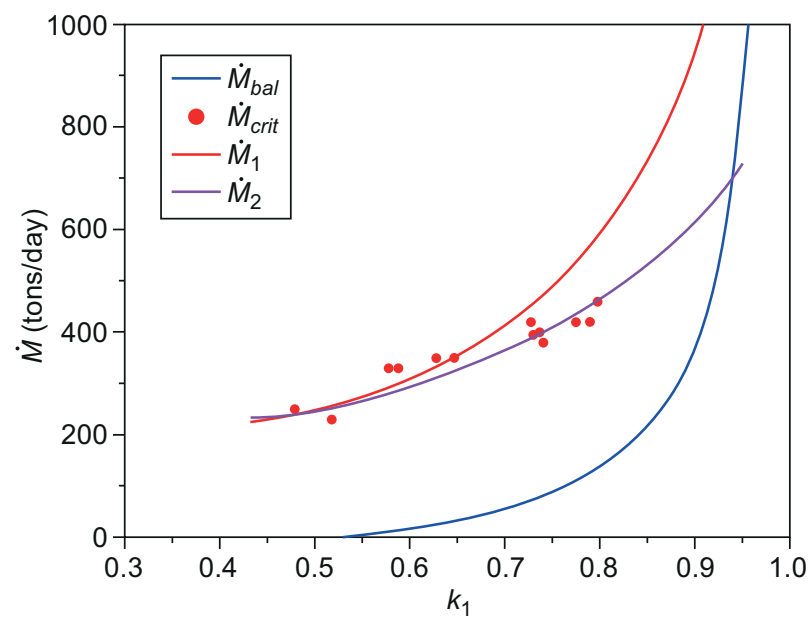

Figure 10. The dependences of the numerically calculated values of the critical melting performance $\dot{M}_{c r i t}$ (red points, values from Table 2), the critical performances $\dot{M}_{1}$ and $\dot{M}_{2}$ obtained from the energetic model (Equation 13) for values of $u_{H \text { uniform }}=0.445$ and 0.20 respectively, and the values of $\dot{M}_{b a l}$. $v_{\text {lcref }}$, as well as the values of $H_{M}^{T}, \dot{H}^{L}$, and $\xi$ presented earlier in this work, the theoretical critical performances $\dot{M}_{\text {crit }}\left(k_{1}\right)$ was calculated according to Equation 13. The $\dot{M}_{\text {crit }}\left(k_{1}\right)$ curve is depicted in the following Figure 10 , together with the curve $\dot{M}_{b a l}\left(k_{1}\right)$ and numerically calculated values of $\dot{M}_{\text {crit }}\left(k_{1}\right)$.

Both curves $\dot{M}_{1}\left(k_{1}\right)$ and $\dot{M}_{2}\left(k_{1}\right)$ of the energetic model approximately match the numerical values at lower values of $k_{1}$ but the curve $\dot{M}_{1}\left(k_{1}\right)$ for the theoretical value $u_{\text {Huniform }}=0.445$ deviates from the numerically calculated values at $k_{l}>0.65-0.70$. The possible explanation is that no perfect uniform flow sets up along the curve $\dot{M}_{b a l}$ $\left(k_{1}\right)$ although the energetic conditions for the uniform flow are fulfilled there. As was observed from pictures of the flow character, the local heating and emerging local circulations of the melt were the most probable cause of the deviation from the uniform flow. The other curve $\dot{M}_{2}\left(k_{1}\right)$ with the value of $u_{\text {Huniform }}=0.20$ in Figure 10 shows nevertheless better agreement with the numerical results and facilitates the extrapolation. Following the curve $\dot{M}_{b a l}\left(k_{1}\right)$ for $u_{\text {Huniform }}=0.20$ in Figure 10, the maximal melting performance attainable at its intersection with the curve at $k_{1}=0.94$ is 728 tons/day. However, the problems with batch conversion and heating technique would arise; hence, a value of about 700 tons/day could be considered as a theoretical limit only.

Other results of authors of this work confirm that the maximal value of the space utilization attainable under energetically balanced conditions depends on both the needed heating intensity and the arrangement of the heating elements. Whereas the maximal values of the space utilization $u_{D}$ were attained around 0.45 in the small electrically heated melting module without batch $\left(H_{M}^{T}=126.9 \mathrm{~kJ} \cdot \mathrm{kg}^{-1}[30]\right)$, the maximal value of the space utilization was 0.36 in the same module with simulation of the batch by the level input of cool glass $\left(H_{M}^{T}=571 \mathrm{~kJ} \cdot \mathrm{kg}^{-1},[28]\right)$. The same quantity could even be only 0.20 in a real furnace with the batch blanket examined in this work where $H_{M}^{T}=2290 \mathrm{~kJ} \cdot \mathrm{kg}^{-1}$. The values of the highest utilization thus depended on the value of $H_{M}^{T}$. It seemed that also a detailed distribution of heating elements in both parts of the space played its role. Consequently, the cautious investigation of the transversal and vertical distribution of heating energy and the character of the heating elements may contribute to maximal utilization values, as well.

Two main aspects should be considered when trying to increase the melting performance: the impact of the melting kinetic and the character of the melt flow indicated by the position of the value of $\dot{M}_{\text {crit }}$ with respect to the curve $\dot{M}_{b a l}\left(k_{1}\right)$ in the graph $\dot{M}\left(k_{1}\right)$. As is obvious from the derivation of equation (13), the critical melting performance is a function of $k_{l}$. When $k_{l}$ is growing, the values of $\dot{M}_{c r i t}$-attained in the region above the curve $\dot{M}_{b a l}$ $\left(k_{1}\right)$ - approach this curve and space utilization should grow progressively whereas the values of $\tau_{\text {Href }}$ remain almost constant. The growth is indicated by Equation 13 
and proved by the results in $[28,30]$ and by the curve $\dot{M}_{2}\left(k_{1}\right)$ in Figure 10 of this work. Thus, the increase of $k_{l}$ in the interval up to the $\dot{M}_{b a l}$ curve is a very efficient factor of melting performance. If only the melting kinetics is improved, i.e. the $\dot{M}_{\text {crit }}$ values should grow under constant $k_{l}$ (e.g., by the optimal dose of fining agents or by the use of fine sand), the growth of the critical melting performance is damped by the simultaneous decrease of the space utilization owing to increase of the value of $v_{l c}$. However, the faster melting kinetics increases the through flow velocity and, on the contrary, increases the space utilization. Both effects partially compensate and the degree of compensation should be verified.

The shift of the curve $\dot{M}_{b a l}\left(k_{1}\right)$ to the left and its straightening improve the melting performance. According to Equation 7, the shift of the dependence to the left is realized by minimizing $\xi$, i.e. by decreasing the fraction of heat losses in the batch region. The shift of the curve facilitates an approach of the calculated numerical values to the $\dot{M}_{b a l}$ curve at lower $k_{l}$. Practically, it means that either the batch region should be well insulated, temperatures inside should be lower and/or the insulation would partially be stripped in the free level region. The straightening of the $\dot{M}_{b a l}$ curve is attainable if the total heat losses are high and, on the contrary, if the theoretical heat is low. The above-mentioned requirements lead to a partial strip of the space insulation in the free level region, particularly of the side walls (which simultaneously supports the spiral flow), and application of preheated batch or batch conversion in a separate space. Figure 11 presents the values of $\dot{M}_{b a l}$ corresponding to Figure 10 (curve 1) along with the optimized $\dot{M}_{b a l}$ (curve 2). The latter was obtained under the assumption that heat losses in the batch region were preserved and the heat losses in the free level region were increased by $50 \%$; consequently, the value of $\xi$ decreased from 0.534 to 0.433 . The total heat losses increased from $2654 \mathrm{~kW}$

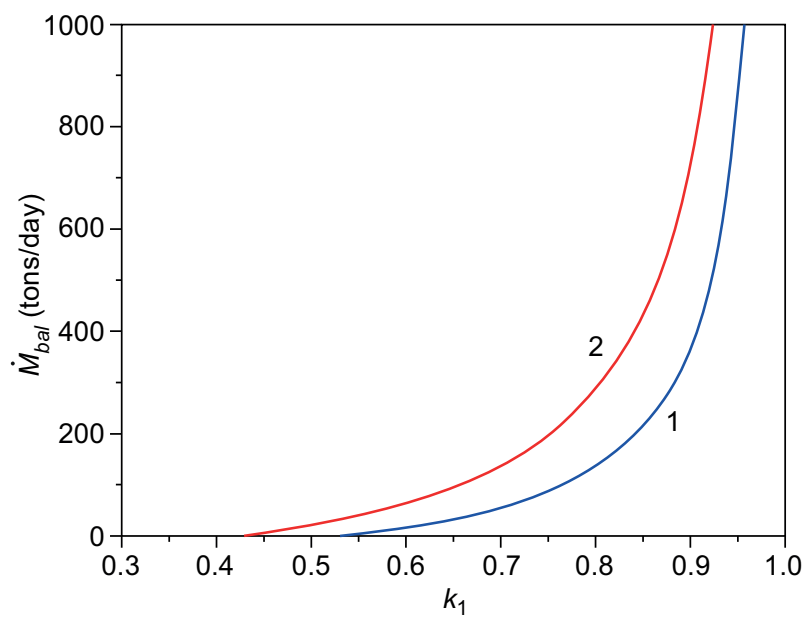

Figure 11. The $\dot{M}_{b a l}\left(k_{1}\right)$ curves for the melting space. 1 - the original curve (see curve $\dot{M}_{b a l}$ in Figure 10), 2 - the curve with the values $\xi=0.433, H^{L}=3272 \mathrm{~kW}, H_{M}^{T}=1846 \mathrm{~kJ} \cdot \mathrm{kg}^{-1}$. to $3272 \mathrm{~kW}$. In addition, the batch was preheated to $350^{\circ} \mathrm{C}$; consequently, the value of $H_{M}^{T}$ decreased from $2290 \mathrm{~kJ} \cdot \mathrm{kg}^{-1}$ to $1846 \mathrm{~kJ} \cdot \mathrm{kg}^{-1}$. The apparent difference between both curves supports the expectation that the maximal value of the melting performance (at the intersection of curves $\dot{M}_{b a l}\left(k_{1}\right)$ and $\dot{M}_{c r i t}\left(k_{1}\right)$ ) will be attained at obviously lower values of $k_{l}$.

\section{CONCLUSION}

The presented calculation results demonstrate that the proper distribution of energy in a current type of the horizontal industrial furnace can noticeably increase the melting performance. This fact implies also the decrease of the specific energy consumption. Along with energy transfer, both longitudinal and transversal energy barriers formed by the electric boosting were examined - the longitudinal ones having priority owing to support of the helical flow. Nevertheless, only the transport of energy under the batch blanket proved to have a clear beneficial effect. It seems, however, that the adjustment of the helical flow should beneficially affect the detailed character of the longitudinal circulations. The best result in this series of calculations - being twice the original one - was obtained for the case simulating the helical flow. The presented energetic model allowed the diagram of the flows in the dependence $\dot{M}\left(k_{1}\right)$ and facilitated the extrapolation of the melting performance to the theoretical limit value being around 700 tons/day.

In the near future, the main effort in the field of flow control should be focused on the homogeneous heating of the batch and melt, as well as increasing effect of the helical flow. The substantial increase of the batch conversion capacity to balance the high melting performance of the melt is another urgent task.

\section{Acknowledgement}

This work has been supported by the project No. TH02020316 "Advanced technologies of glass production" of Technology Agency of the Czech Republic and by the Specific University Research (MSMT No. 20SVV/2017).

\section{REFERENCES}

1. Readey D. W., Cooper A. R. (1966): Molecular diffusion with a moving boundary and spherical symmetry. Chemical Engineering Science, 21(10), 917-\&.

2. Hrma P. (1980): A Kinetic-equation for interaction between grain material and liquid with application to glass melting. Silikáty, 24(1), 7-16.

3. Bodalbhai L., Hrma P. (1986): The dissolution of silica grains in isothermally heated batches of sodium-carbonate and silica sand. Glass Technology, 27(2), 72-78. 
4. Hrma P., Marcial J., Swearingen K. J., Henager S. H., Schweiger M. J., TeGrogenhuis N. E. (2011): Conversion of batch to molten glass, II: Dissolution of quartz particles. Journal of Non-Crystalline Solids, 357(3), 820-828. doi: 10.1016/j.jnoncrysol.2010.11.096

5. Hrma P., Marcial J. (2011): Dissolution retardation of solid silica during glass-batch melting. Journal of Non-Crystalline Solids, 357(15), 2954-2959. doi: 10.1016/j.jnoncrysol.2011.03.041

6. Cable M. (1960): Further data showing the effect of sand grain size on the refining of a glass. Glass Technology, 1(4), 139-143.

7. Cable M. (1960): Study of refining I. Glass Technology, 1(4), 144-154.

8. Cable M. (1960): Study of refining III. Glass Technology, 2(4), 151-158.

9. Mulfinger H. O. (1972): Behavior of bubbles during glass melting. Glastechnische Berichte, 45(6), 238-243.

10. Němec L., Mühlbauer M. (1981): Verhalten von Glas Blasen in der Glasschmelze bei konstanter Temperatur. Glastechnische Berichte, 54(4), 99-108.

11. Beerkens R. (2003): Analysis of advanced and fast fining processes for glass melts. Proceedings of the $7^{\text {th }}$ Int. Conference on Advances in Fusion and Processing of Glass. Rochester, NY, Ceramic Transactions, 141, 3-34.

12. Němec L., Mühlbauer M. (1983): The concentration field of sand in the glass tank furnace for flat glass. Glastechnische Berichte, 56K, 82-87.

13. Beerkens R., Muijsenberg E., Vanderheijden T. (1994): Modeling of sand grains dissolution in industrial glass melting tanks. Glastechnische Berichte - Glass Science and Technology, 67(7), 179-188.

14. Balkanli B., Ungan A. (1996): Numerical simulation of bubble behaviour in glass melting tanks. 4. Bubble number density distribution. Glass Technology, 37(5), 164-168.

15. Oda K., Kaminoyama M. (2009): Mathematical model of bubble number density in glass tank furnace. Journal of the Ceramic Society of Japan, 117(6), 736-741.

16. Cooper A. R. (1986): A theory of continuous glass making. Part 1: Some initial considerations. Collected Papers XIV ${ }^{\text {th }}$ International Congress on Glass, New Delhi, India.

17. Mulholland V. (1937): Glass making apparatus and method. U.S. Patent 2,068,925.

18. Penberthy H. L. (1966): Glass furnace with means to agitate the molten glass. U.S. Patent 3,268,320.

19. Atkeson F. V. (1967): Method and apparatus for generating currents in molten glass. U.S. Patent 3,305,340.

20. Takashi Y. (1980): Glass melt convection increasing methods. Japanese Patent S55,116,632.

21. Heurtey S. (2000): Perfectionnements apportes aux fours de fusion et d'affinage de verre. French Patent 2,787,784 A1.

22. Boettner G. B. (1991): Method for fining molten glass. U.S. Patent 4,994,099.

23. Polák M., Němec L. (2011): Glass melting and its innovation potentials: The combination of transversal and longitudinal circulations and its influence on space utilisation. Journal of Non-Crystalline Solids, 357(16-17), 3108-3116. doi: 10.1016/j.jnoncrysol.2011.04.020

24. Cincibusová P., Němec L. (2012): Sand dissolution and bubble removal in a model glass-melting channel with melt circulation. Glass Technology: European Journal of Glass Science and Technology Part A, 53(4), 150-157.

25. Němec L., Cincibusová P. (2012): Sand dissolution and bubble removal in a model glass melting channel with a uniform melt flow. Glass Technology: European Journal of Glass Science and Technology Part A, 53(6), 279-286.

26. Polák M., Němec L. (2012): Mathematical modelling of sand dissolution in a glass melting channel with controlled glass flow. Journal of Non-Crystalline Solids, 358(9), 12101216. doi:10.1016/j.jnoncrysol.2012.02.021

27. Cincibusová P., Němec L. (2015): Mathematical modelling of bubble removal from a glass melting channel with defined melt flow and the relation between the optimal flow conditions of bubble removal and sand dissolution. Glass Technology: European Journal of Glass Science and Technology Part A, 56(2), 52-62.

28. Jebavá M., Dyrčíková P., Němec L. (2015): Modelling of the controlled melt flow in a glass melting space: Its melting performance and heat losses. Journal of Non-Crystalline Solids, 430, 52-63. doi:10.1016/j.jnoncrysol.2015.08.039

29. Němec L., Vernerová M., Cincibusová P., Jebavá M., Kloužek J. (2012): The semiempirical model of the bubble behaviour in glass melts. Ceramics-Silikáty, 56(4), 367-373.

30. Hrbek L., Kocourková P., Jebavá M., Cincibusová P., Němec L. (2017): Bubble removal and sand dissolution in an electrically heated glass melting channel with defined melt flow examined by mathematical modelling. Journal of Non-Crystalline Solids, 456, 101-113. doi: 10.1016/j.jnoncrysol.2016.11.013 